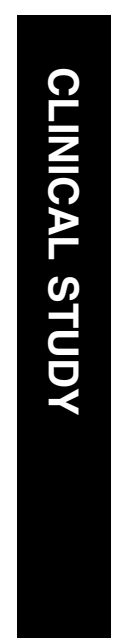

\section{Visual impairment in elderly patients with hip fracture: causes and associations}

${ }^{1}$ Department of

Ophthalmology

Ninewells Hospital

Dundee, UK

${ }^{2}$ Tennent Institute of Ophthalmology

Gartnavel General Hospital

Glasgow, UK

${ }^{3}$ Department of

Ophthalmology

Fife Acute Hospitals

NHS Trust

Queen Margaret Hospital

Dunfermline, UK

Correspondence: A Cox

Department of

Ophthalmology

Ninewells Hospital

Dundee DD19SY, UK

Tel: + 441382496469

Fax: + 441382632893

E-mail: alan.cox@

tuht.scot.nhs.uk

Received: 13 November 2003

Accepted: 29 March 2004

Published online: 27 August 2004

Part funded by grant from Centre for Health and Social Research, Fife.

Presented at British Geriatric society, London, October 2002.

Poster at Royal College of Ophthalmology Congress 2003.

\begin{abstract}
Aims To evaluate the current visual status and ophthalmic history of a sample of elderly patients with fractured neck of femur and to study the relationship between visual status and demographic factors.

Methods A four-centre study of all patients admitted to hospital with fractured neck of femur. The setting was two district (Ayr, Dunfermline) and two teaching (Glasgow, Dundee) hospitals in Scotland. The study examined 537 patients aged 65 years and over admitted with acute fractured neck of femur to hospital.
\end{abstract}

Results Bilateral visual impairment (binocular visual acuity worse than 6/12) was found in 239 of 518 patients (46\%). Of this group, the principal causes for visual deficit were untreated cataract $(49 \%)$, macular degeneration $(21 \%)$, uncorrected refractive error $(\mathbf{1 7 \%})$, and glaucoma $(3 \%)$.

The visually impaired group were more likely to have symptomatic visual complaints ( 58 vs $26 \%$ ), however, were less likely to be under optometric care (71 vs 85\%). A higher proportion of the group with visual impairment lived in areas of social deprivation

Conclusions Patients with fractured neck of femur represent a frail elderly group that have poorer vision than that documented in any other elderly population. The visual defect was potentially remediable in the majority of cases but this group of individuals are not generally in touch with the ophthalmic services. Social deprivation appears to be associated with this groups' inability to access ophthalmic care.

Eye (2005) 19, 652-656. doi:10.1038/sj.eye.6701610

Published online 27 August 2004

Keywords: visual impairment; falls; fractured neck of femur patients; social deprivation (40 vs $26 \%$ ).
A Cox', A Blaikie', CJ MacEwen', D Jones², K Thompson², D Holding ${ }^{2}$, T Sharma ${ }^{3}$, S Miller ${ }^{3}$, S Dobson ${ }^{3}$ and R Sanders ${ }^{3}$
Introduction

Undiagnosed and untreated visual deficit in the elderly British population has been previously reported and it is estimated that between 15 and $30 \%$ of the elderly population aged 65 years and over suffer from visual impairment. ${ }^{1-3}$ The WHO classification of visual impairment is a binocular best-corrected visual acuity of worse than $6 / 18 .{ }^{4}$ However, this definition of visual impairment after correction for refractive error underestimates the true prevalence of visual impairment as applicable to the general population in every day life. In addition, there is evidence that a visual acuity worse than $6 / 12$ can be associated with significant morbidity. ${ }^{5}$ It is therefore common to define visual impairment as a 'presenting' binocular visual acuity worse than $6 / 12 .^{3,6}$

The aetiology of falls in the elderly is multifactorial of which visual deficit has been identified to be one of the predisposing factors. ${ }^{78}$ Approximately $40-60 \%$ of falls in the elderly lead to injury of which $30-50 \%$ are minor, 5\% major and 5\% fractures. ${ }^{9} \mathrm{~A}$ hip fracture carries with it significant resultant morbidity, mortality and cost to the health services. ${ }^{9}$ Fall-related accidents are the precipitating event in $40 \%$ of admissions to long-term institutional care in the elderly. ${ }^{10}$

The aim of our study was to evaluate the visual status and ophthalmic history in a group of frail elderly patients who had suffered a fall. Patients with fractured neck of femur were an ideal study group as they represented a cross section of the frail elderly, are clearly defined and easily identified. In the UK, a similar group of patients had their visual status evaluated over two decades ago. ${ }^{11,12}$ At that time $0.8 \%$ of patients with fractured neck of femur were totally blind and $21 \%$ were partially sighted. The causative ocular pathology was not documented. In the 75-84 years age group, $42 \%$ had not seen an optician in the past 5 years. 
Since this time, there has been a major expansion in both the hospital- and community-based ophthalmic services in the UK together with a rise in the rate of cataract surgery. ${ }^{13}$ In addition to this, since 1990 general practitioners have been required to offer an annual screening assessment that includes visual assessment to all patients aged 75 years and over. ${ }^{14}$ We therefore felt it was appropriate to re-evaluate this group of the frail elderly.

\section{Methods}

A four-centre cross-sectional study was carried out over a period of 1 year (June 2000-June 2001) in two district general (Ayr, Dunfermline) and two teaching (Glasgow, Dundee) hospitals. In each of these centres, patients aged 65 years and over admitted with fractured neck of femur were consented to partake in an ophthalmic and social history questionnaire and ophthalmic examination. Approval was sought and granted from the Ethical Committees in each hospital. Patients were recruited into the study on 1 day of the week. This was a different day of the week in each centre and was determined by preexisting clinical commitments. Patients were interviewed and examined between 3 and 5 days following hip surgery since at this time the patients were mobile enough to facilitate examination. This in effect meant that there was only a 2 day 'window' during which patients were eligible for entry into the study, otherwise patients who were admitted for a longer duration (and so were presumably frailer) could bias the study by being given more opportunities to enter the study. The researcher taking the history and performing the ophthalmic examination was consistent throughout the year study period in each centre. If ocular pathology requiring immediate attention was found the patient was treated by the ophthalmic consultant in each centre. If nonurgent pathology was found a routine referral to the eye clinic was made.

Each patient's mental state was assessed using an abbreviated mental test and given a grading of normal, moderately impaired, or demented. ${ }^{15}$ Details were then filled on demographic, social, ophthalmic, and fall history.

Ophthalmic history included the presence or absence of visual complaints (that included reading printed matter and signs, recognising faces, watching television, and seeing steps and curbs), past ocular history, whether the patient was currently under the care of ophthalmic services and the time of the last visit to the optician or hospital eye services. Fall history was obtained including the number of previous falls and fractures sustained in the 5 years preceding the current hip fracture.
Visual acuity was checked with a Snellen chart uniocularly and binocularly with and without spectacles and with pin hole. Binocular 'presenting' vision is quoted and this was defined as the binocular vision obtained with the spectacle correction that the patient currently possessed. If the patient did not own a pair of glasses binocular vision was measured unaided. Visual fields were assessed using the confrontation method. The anterior and posterior segments of each eye were examined using a free standing or portable slit lamp, noncontact retinal lens and ophthalmoscope. Pupillary responses were checked before dilation. Intraocular pressure was measured using a Goldman's tonometer or a tonopen.

The presence of cataract was graded in accordance with the Lens Opacities Classification System and was given a grading of clear, early, and moderate opacification and an additional classification of dense opacification when no fundal details were discernable. ${ }^{16}$ Macular degeneration was diagnosed by examination of the fundus. Refractive error was recorded if the pin-hole vision was better by at least one line on the Snellen chart than the patient's current best-corrected visual acuity in the absence of other ocular pathology. Glaucoma was diagnosed if two out of three diagnostic criteria were fulfilled (optic disc cupping, raised intraocular pressures, or glaucomatous visual field defect). Other diagnostic categories identified were diabetic eye disease, arterial or venous occlusion, optic neuropathy, and a small group of miscellaneous conditions. The presence of the above classes of pathology were documented and ranked in order of the degree to which the examining clinician felt they contributed to any visual deficit.

Data were collected on standardised forms that were scanned and imported into an Excel spreadsheet. All data scanned were manually validated, where parametric tests were applied normality was tested using the Shapiro-Wilk test. Where categorical variables were compared a Pearson's $\chi^{2}$-test was used. Where means were compared, Student's $t$-test for independent samples was used.

\section{Results}

In all, 537 patients were recruited in the study. During this time, 1521 patients were admitted in the four centres with a diagnosis of fractured neck of femur; the study group therefore represents $35 \%$ of all patients. A total of 19 patients were excluded due to severe cognitive impairment as a result of which an accurate visual acuity was not possible. The total number of patients analysed were therefore 518. The numbers in each centre were; Fife (199), Dundee (120), Ayr (101), and Glasgow (117). 
The binocular presenting visual acuity for the group was $6 / 18$ or poorer in $239(46 \%)$ patients and we shall refer to this group as the visually impaired group. In all, $279(54 \%)$ patients achieved a binocular visual acuity of $6 / 12$ or better. The binocular best-corrected vision was recorded with spectacle correction when the patient possessed this. This is an approximation of the patients 'walk-around' vision as patients may own a pair of spectacles but not wear them, however, it was felt that recall bias would make any other measure of their functional vision unreliable. The demographics of the two groups are compared in Table 1.

The principal cause of visual impairment in the visually impaired group was cataract in 118 (49\%), refractive error in a further $40(17 \%)$ patients, and macular degeneration in 51 (21\%) (Figure 1).

The visually impaired group were older (mean age 85 vs 79 years) and more likely to be admitted from long-term institutional care (28 vs 6\%). There was also a

Table 1 Comparison of patients with visual impairment vs patients without visual impairment

\begin{tabular}{|c|c|c|c|}
\hline & $\begin{array}{l}\text { Visually } \\
\text { impaired } \\
\text { group } \\
(n=239)\end{array}$ & $\begin{array}{l}\text { Non visually } \\
\text { impaired } \\
\text { group } \\
(n=279)\end{array}$ & Significance \\
\hline Mean age & 85 years & 79 years & $P<0.001$ \\
\hline \multicolumn{4}{|l|}{ Sex } \\
\hline Male & $48 / 239(20 \%)$ & $73 / 279(26 \%)$ & \\
\hline Female & $191 / 239(80 \%)$ & $206 / 279(74 \%)$ & \\
\hline \multicolumn{4}{|c|}{ Domestic circumstance } \\
\hline Live alone & $105 / 239(44 \%)$ & $159 / 279(57 \%)$ & $P<0.001$ \\
\hline Partner or relative & $67 / 239(28 \%)$ & $103 / 279(37 \%)$ & \\
\hline Long-term & $67 / 239(28 \%)$ & $17 / 279(6 \%)$ & \\
\hline institutional care & & & \\
\hline \multicolumn{4}{|l|}{ Cognitive function } \\
\hline Normal & $138 / 239(58 \%)$ & $243 / 279(87 \%)$ & $P<0.001$ \\
\hline $\begin{array}{l}\text { Moderately } \\
\text { impaired }\end{array}$ & $65 / 239(27 \%)$ & $28 / 279(10 \%)$ & \\
\hline $\begin{array}{l}\text { Severely } \\
\text { impaired }\end{array}$ & $36 / 239(15 \%)$ & $8 / 279(3 \%)$ & \\
\hline $\begin{array}{l}\text { Contact with } \\
\text { optometrist } \\
\text { in the preceding } \\
3 \text { years }\end{array}$ & $158 / 222(71 \%)$ & $236 / 279(85 \%)$ & $P<0.001$ \\
\hline Visual complaints & $136 / 233(58 \%)$ & $73 / 279(26 \%)$ & $P<0.001$ \\
\hline $\begin{array}{l}\text { One or more falls } \\
\text { in preceding } 5 \text { years }\end{array}$ & $140 / 218(64 \%)$ & $133 / 272(49 \%)$ & $P<0.001$ \\
\hline $\begin{array}{l}1998 \text { Scottish } \\
\text { deprivation index } \\
\text { score }>9\end{array}$ & $96 / 239(40 \%)$ & $73 / 279(26 \%)$ & $P<0.001$ \\
\hline
\end{tabular}

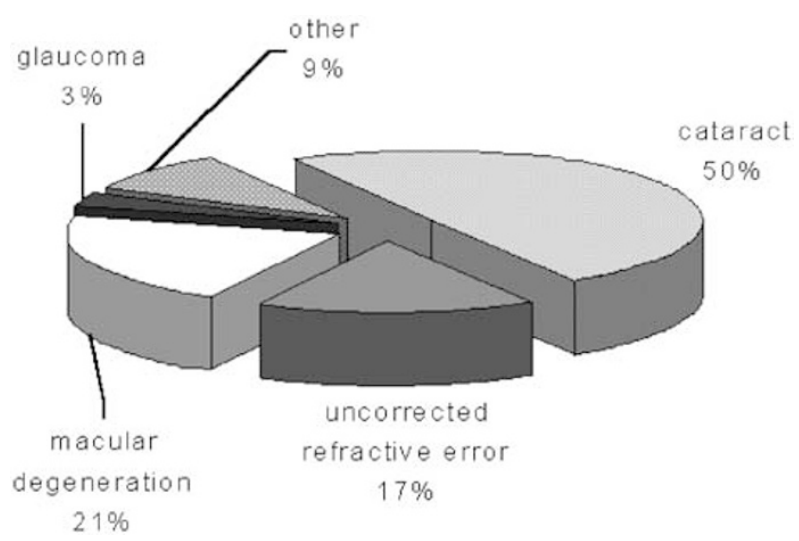

Figure 1 Principal cause of visual impairment.

higher rate of severe cognitive impairment in this group (15 vs 3\%).

The Scottish deprivation index is a postcode-based indicator of social deprivation and a score greater than nine is considered to represent significant social deprivation. ${ }^{17}$ Using this score, the visually impaired group was more likely to reside in an area of social deprivation (40 vs 26\%).

The mode of fracture was traumatic in $97 \%$ of patients in both groups. Patients in the visually impaired group were more likely to recall suffering a fall in the preceding 5 years (64 vs 49\%) and were more likely to have fractured their fellow hip (9 vs 5\%).

$136(58 \%)$ patients in the visually impaired group admitted to visual complaints that were adversely affecting their quality of life compared to $73(26 \%)$ of the nonvisually impaired group. However, the visually impaired group was less likely to have sought the assistance of an optometrist in the preceding 3 years (71 vs $85 \%$ ). Those with a deprivation score $>9$ were similarly less likely to have sought the assistance of an optometrist in the preceding 3 years ( 71 vs $82 \%, P<0.01$ ).

Only 39 patients $(16 \%)$ among the visually impaired group were presently under the care of eye services and nine of these (4\% of the visually impaired group) were on the waiting list for cataract surgery.

\section{Discussion}

To our knowledge, this study represents the poorest level of vision documented in a sample of elderly patients with fall, in the Western world. It supports other work that has demonstrated undetected and untreated visual impairment in the elderly, despite expansion and advances in ophthalmic services. ${ }^{1,2}$ Among our group, $46 \%$ were visually impaired and the principal cause for this in $49 \%$ of this group was untreated cataract. Other studies have shown that there is a large pool of 
potentially treatable vision impairing cataract in the elderly aged 65 years and older, reflecting a significant shortfall in cataract surgery. ${ }^{18}$

Macular degeneration was the principal diagnosis in $21 \%$ (51) of those with visual impairment. Of this group, seven were currently under the care of the eye services and 16 had previous ophthalmic attention for macular degeneration. Over half the group (28) had not received any ophthalmic care indicating a failure to access ophthalmic services. Many of these patients had coexistent disease such as cataract and as such may benefit from surgery. In this visually impaired group, 26 out of $51(50 \%)$ patients had cataract as the secondary diagnosis and two patients had cataract as the principal codiagnosis.

Of those with visual impairment, 17\% (40) had an uncorrected refractive error with 23 patients having no spectacles at all and others having spectacles that had not been updated for several years. This figure is disheartening and reflects either the inability or possible reluctance to seek attention. These patients were certainly aware of their visual deficit as $58 \%$ had visual complaints.

The visual-impaired group were older and this may partly explain some of the results as older patients tend to be frailer and so less able to access services. Cognitive impairment was certainly more common among the visually impaired group with $15 \%$ suffering from severe cognitive impairment. However, the vast majority of this group were able to cooperate with, and benefit from, any ophthalmic intervention. It is not the case that this is a group of patients known to the ophthalmic services but deemed too frail for intervention.

Falls and femoral fractures are multifactorial processes and both falls and visual impairment are more common in the more frail and elderly members of the community. We would therefore be cautious in suggesting that the association between fractured neck of femur and visual impairment is causal or that treatment of the visual impairment would be an effective preventative strategy. However, the purpose of this study was to document the level and cause of visual impairment in this population and has identified that the visual function is much poorer than would be expected compared to the general population of the same age.

Why have ophthalmic services failed to reach this group of elderly patients? The reasons are probably multifactorial. In those with coexistent morbidity visual symptoms may be less evident to carers than other problems and may be tolerated by those affected and thus given low priority. Beyond a certain stage of disability elderly patients are probably unable to seek an optician's examination. Others are dependent on relatives or carers for attention. Patients living in an institution or who are mentally impaired are particularly vulnerable. In our study $28 \%$ in the visually impaired group lived in an institution compared to $6 \%$ in the fellow group. Most agree that the introduction of a fee for the sight test in 1990 was unhelpful in promoting visual health in the elderly and fear of costs has been repeatedly cited by a proportion of the elderly as a barrier to attending an optician and obtaining spectacles. ${ }^{19}$ Certainly, the higher level of social deprivation among the visually impaired is telling in this respect. Given that more of the visually impaired group came from institutional care homes, which tend to be located in lessdeprived areas, we have probably in fact underestimated the true magnitude of this association. This association between social deprivation and reluctance to seek optometric assistance was maintained irrespective of visual impairment. The 75-year-old check carried out by general practitioners includes assessment of vision. Unfortunately, there has been wide variation in the uptake of this test, low overall awareness of its existence and poor specification of how and why vision should be assessed. $^{18}$

Ophthalmic services are expanding, but this and other work indicate that they are tending to serve the 'fitter' elderly. ${ }^{13}$ Cataract surgery rates have doubled but so have the rates of second eye cataract surgery together with a falling threshold for surgery particularly in younger patients. ${ }^{13}$ These features indicate that those able to access these services will be better placed to benefit from them.

The remit of eye care in the elderly is divided among general practitioner, optometrist, and ophthalmologist with each being interdependent on each other and all heavily dependent on the patient initiating attention. This existing system clearly fails the frail elderly. ${ }^{2}$ The 75-year-old check by GPs should be given more support with specific guidelines. The $\mathrm{WHO}$ recommends that a visual acuity worse than 6/12 warrants optician or ophthalmic referral. ${ }^{6}$ Home visits by opticians seem to be a rarity and many patients in this study were unaware of the existence of such a service. Spectacle costs should be easily affordable or assisted for the elderly.

Visual acuity in patients with fractured neck of femur was last assessed 20 years ago ${ }^{11,12}$ and found to be very poor. The situation remains unchanged decades later with many of the more frail and vulnerable elderly suffering from troublesome but correctable visual impairment, and either unwilling or unable to access the ophthalmic services that they need.

\section{Acknowledgements}

This work was supported by grant from Centre of Health and Social Research, Glenrothes. 
10 Kennedy TE, Coppard LC. The prevention of falls in later life. Dan Med Bull 1987; 34: 1-24.

11 Brocklehurst JC, Exton-Smith AN, Lempert BSM, Hunt LP, Palmer MK. Fracture of the femur in old age: A two-centre study of associated clinical factors and the cause of the fall. Age Ageing 1978; 7: 7-15.

12 Wooton R, Bryson E, Elsasser V, Freeman H, Green JR, Hesp $\mathrm{R}$ et al. Risk factors for fractured neck of femur in the elderly. Age Ageing 1982; 11: 160-168.

13 Gray DC, Crabtree HL, O'Connell JE, Allen ED. Waiting in the dark: cataract surgery in older people. BMJ 1999; 318: 1367-1368.

14 Smeeth L, Iliffe S. Effectiveness of screening older people for impaired vision in community setting: systematic review of evidence from randomised controlled trials. BMJ 1998; 316: 660-663.

15 Royal Society of Physicians of London and the British Geriatric Society. Standardised Assessment Scales for Elderly People. London, 1992.

16 Chylack Jr LT, Leske MC, Sperduto R, Khu P, McCarthy D, LOCS Research Group. Lens Opacities Classification System. Arch Ophthalmol 1988; 106: 330-334.

17 McLoone P. Carstairs scores for Scottish postcode sectors from the 1991 Census. Public Health Research Unit. http:/www.msoc-mrc.gla.ac.uk/.

18 Minassian DC, Reidy A, Desai P, Farrow S, Vafidis G, Minnassian A. The deficit in cataract surgery in England and Wales and the escalating problem of visual impairment: epidemiological modelling of the population dynamics of cataract. Br J Ophthalmol 2000; 84: 4-8.

19 Webster FWA, Barnes G. Eye tests in the elderly: factors associated with attendance and diagnosis yield in non-attenders. J R Soc Med 1992; 85: 614-616.
Musad T, Morris RO. Epidemiology of falls. Age Ageing 2001; 30-S4: 3-7. 